\title{
Konsepsi Manusia Seutuhnya Dalam Kitab al-Insan al-Kamil Karya Abdul Karim al-Jili
}

\author{
Haris Kurniawan ${ }^{1}$, Abas Mansur Tamam ${ }^{1}$, Abdul Hayyie Al-Kattani ${ }^{1}$ \\ ${ }^{1}$ Universitas Ibn Khaldun Bogor, Indonesia \\ *haris.uika69@gmail.com \\ abbasmanta@yahoo.co.id \\ alkattani@gmail.com
}

\begin{abstract}
Abstrak
Dalam pandangan Islam, pendidikan yang utama adalah yang dapat memanusiakan manusia sesuai dengan kodrat kemanusiaannya. Pendidikan yang dapat menempatkan manusia pada relnya. Pendidikan yang dapat mengangkat jati diri manusia sehingga mendapatkan esensinya sebagai manusia, menjadi manusia seutuhnya, manusia yang dapat menjalankan peran dan fungsinya, baik secara vertikal sebagai hamba Allah (abdullah), maupun secara horizontal dalam hubungan sosial kemanusiaan (khalifatullah). Fokus dari penelitian ini adalah untuk menganalisis konsep Manusia Seutuhnya dalam Kitab al-Insan al-Kamil karya Abdul Karim al-Jili. Metode yang digunakan dalam penelitian ini adalah metode penelitian kualitatif non interaktif, jenis penelitian studi kepustakaan (library research) dengan menggunakan analisis konten (content analysis) dan analisis historis (history analysis). Insan kamil merupakan ajaran tasawuf al-Jili yang merupakan pengembangan dari konsep tasawuf Ibn 'Arabi yaitu wahdat al-wujud. Pandangan mengenai wahdat al-wujud tidak dimaknai secara leterlek/tekstual bersatunya dua dzat yang berbeda ke dalam satu wujud, melainkan suatu makna di mana seorang sufi dapat menyerap asma' dan sifat-sifat Tuhan sebanyak-banyaknya (al-Takhalluq bi akhlaq Allah) sehingga terjadinya transformasi spiritual. Seorang sufi mengalami fana' dalam asma', sifat, dan dzat Tuhan. Seluruh gerak langkah dalam kehidupannya senantiasa dipusatkan pada apa yang diinginkan Tuhan (ridha' Allah).
\end{abstract}

Kata Kunci: Konsepsi, Manusia, Seutuhnya

\begin{abstract}
In the view of Islam, the main education is that which can humanize humans according to their human nature. Education that can put humans on the rails. Education that can elevate human identity so that it gets its essence as a human being, becoming a perfect human being, a human being who can carry out his roles and functions, both vertically as servants of Allah (abdullah), and horizontally in human social relations (khalifatullah). The focus of this research is to analyze the concept of the Perfect Man in the Book al-Insan al-Kamil by Abdul Karim al-Jili. The method used in this research is a non-interactive qualitative research method, a type of library research using content analysis and historical analysis.
\end{abstract}


Insan kamil is the teaching of tasawuf al-Jili which is the development of the concept of tasawuf Ibn 'Arabi, namely wahdat al-wujud. The view of wahdat al-wujud is not interpreted textually by the union of two different beings into one form, but rather a meaning in which a sufi can absorb as much asthma 'and God's attributes as possible (al-Takhalluq bi akhlaq Allah) so that it occurs. spiritual transformation. A Sufi experiences fana 'in asthma', the nature, and essence of God. All the steps in his life are always focused on what God wants (rida' Allah).

Keywords: Conception, Human, Perfect.

\section{Pendahuluan}

Manusia dalam sudut pandang pendidikan merupakan obyek sekaligus subyek pendidikan. Sebagai obyek pendidikan, manusia adalah hasil akhir dari proses pendidikan. Sedangkan sebagai subyek pendidikan, manusia merupakan pelaksana dari proses pendidikan, bagaimana menjalankan proses pendidikan agar terwujud manusia seutuhnya.

Pendidikan merupakan faktor penting yang inhern dan mutlak dalam kehidupan manusia, baik secara individu, keluarga, serta bangsa dan negara. Pendidikan adalah usaha yang dijalankan oleh seseorang atau sekelompok orang agar menjadi dewasa atau secara mental mencapai tingkat hidup dan penghidupan yang lebih tinggi. Maju mundurnya suatu bangsa banyak ditentukan oleh maju mundurnya pendidikan bangsa itu. (Sudirman, 1989)

Tentunya, melalui pendidikan diharapkan nilai-nilai utama dalam diri manusia akan semakin terasah, muncul ke permukaan, serta hidup dalam diri manusia itu melalui pengembangan segenap potensi yang dimiliki, sehingga peran dan fungsi manusia akan tetap berada di jalurnya yang benar sebagai manusia.

Dalam pandangan Islam, pendidikan yang utama adalah yang dapat memanusiakan manusia sesuai dengan kodrat kemanusiaannya. Pendidikan yang dapat menempatkan manusia pada relnya. Pendidikan yang dapat mengangkat jatidiri manusia sehingga mendapatkan esensinya sebagai manusia, menjadi manusia seutuhnya, manusia yang dapat menjalankan peran dan fungsinya, baik secara vertikal sebagai hamba Allah (abdullah), maupun secara horizontal dalam hubungan sosial kemanusiaan (khalifatullah).

Sejumlah konsep atau definisi dari para pakar/ahli yang memiliki kapasitas dan kompetensi di bidangnya telah melahirkan sejumlah teori ilmiah tentang manusia. Dalam literatur pendidikan Islam, Al-Qur'ān dan Hadits adalah landasan utama sebagai konsep dasar dalam memaknai berbagai dimensi kehidupan manusia yang di dalamnya banyak terdapat petunjuk-petunjuk tentang penciptaan manusia, bagaimana manusia diciptakan, apa peran dan fungsi manusia diciptakan, dan secara keseluruhannya untuk apa manusia diciptakan, dan lain sebagainya.

Muhaimin mengemukakan, bahwa hakikat manusia itu ada karena ia memiliki sejumlah potensi latent yang diberikan oleh Allah kepadanya, baik jasmani maupun 
ruhani. Dengan demikian pendidikan Islam bercorak teosentris yang bersumber dari dan bersandar pada wahyu Ilahi. (Muhaimin, 2003)

Manusia sebagai makhluk ciptaan Allah SWT yang istimewa, memang memiliki latar belakang kehidupan yang penuh rahasia. Lembaran-lembaran kitab suci Al-Qur'ān yang memuat petunjuk Ilahi tentang penciptaan manusia memuat sejumlah informasi, baik yang tersurat (jelas maknanya) maupun tersirat (perlu penafsiran) tentang hakikat manusia ini. Manusia selaku makhluk ciptaan dengan segala fungsi dan peran yang harus dilakukannya, semuanya diinformasikan dalam kitab suci. (Jalaluddin, 2003)

Manusia dalam bahasa Inggris disebut man (asal kata dari bahasa Anglo Saxon, man) yang kemudian dihubungkan dengan mens (Latin), yang berarti "ada yang berfikir." (Bagus, 1996) Sementara kita menyebutnya manusia, sebagai makhluk berakal budi (mampu menguasai makhluk lain).

Salah satu kelebihan manusia bila dibandingkan dengan makhluk lain adalah memiliki akal fikiran. Bukan hanya sekedar berbeda secara susunan fisik, namun lebih jauh pada aspek psikisnya. Kedua aspek manusia tersebut memiliki potensinya masingmasing yang sangat mendukung bagi proses aktualisasi diri pada posisinya sebagai makhluk sempurna. Potensi material spiritual yang dimilikinya bersifat aktif dan dinamis sesuai perkembangan dan tuntutan zaman di mana manusia berada, menjadikan manusia sebagai makhluk ciptaan Allah SWT yang terbaik. (Martini, 1994) Akal fikiran merupakan ciri khas sekaligus menjadi nama yang disematkan kepada salah satu makhluk di muka bumi ini, dia itulah yang disebut manusia.

Berdasarkan pemaparan latar belakang masalah di atas, penelitian ini membahas “Konsepsi Manusia Seutuhnya Dalam Kitab al-Insan al-Kamil Karya Abdul Karim al-Jili".

Untuk mengetahui sejauh mana obyek kajian dan penelitian terkait Konsepsi Manusia Seutuhnya Dalam dalam Kitab al-Insan al-Kamil Karya Abdul Karim al-Jili, maka dilakukan pra-penelitian terhadap sejumlah literatur. Beberapa penelitian terdahulu yang telah dilakukan peneliti lain tentunya relevan terhadap penelitian ini, di antaranya:

Penelitian yang dilakukan oleh Kiki Muhammad Hakiki dan Arsyad Sobby Kesuma dalam Jurnal Ilmiah Agama dan Sosial Budaya UIN Raden Intan Lampung, Vol. 3 No. 2, 2018 yang berjudul Insan Kamil Dalam Perspektif Abd al-Karim al-Jili dan Pemaknaannya dalam Konteks Kekinian.

Fokus penelitian tersebut berupaya secara khusus mengkaji pemikiran insan kamil perspektif al-Jili dengan menjadikan pemikiran insan kamil Ibn 'Arabi sebagai pembanding dan upaya pemaknaan dalam konteks kekinian.

Persamaan pembahasan dalam jurnal tersebut dengan bahasan penelitian ini adalah sama-sama membahas tentang insan kamil perspektif al-Jili. Perbedaan penelitian yang ditulis oleh Kiki Muhammad Hakiki dan Arsyad Sobby Kesuma membahas tentang pemikiran insan kamil perspektif al-Jili komparatif insan kamil Ibn 'Arabi, sedangkan 
peneliti membahas tentang Konsepsi Manusia Seutuhnya Analisis Kitab al-Insan al-Kamil karya Abdul Karim al-Jili.

Penelitian kedua yang dilakukan oleh Hasnawati dari IAIN Imam Bonjol, Padang. dengan judul Konsep Insan Kamil menurut Pemikiran Abdul Karim al-Jili pada Jurnal Psikologi Islam al-Qalb, Jilid 8, No. 2, 2016. Dalam jurnal tersebut Hasnawati menjelaskan, bahwa pemikiran al-Jili tentang insan kamil merupakan pengembangan konsep insan kamil yang telah dikemukakan oleh Ibn 'Arabi, terutama sekali berasal dari konsep wahdat al-wujud. Meskipun secara epistemologis, wacana insan kamil al-Jili bercorak falsafi, namun kesimpulan yang diperolehnya bernuansa teologis yang bercorak sunni.

Al-Jili masih memberikan penekanan bahwa antara Tuhan dan makhluk terdapat perbedaan yang substansial. Adapun misi dari penjelasan konsep insan kamil al-Jili ini merupakan upaya untuk memperlihatkan bagaimana Tuhan bertajalli pada makhluk. Sebab alam merupakan wujud tajalli Tuhan. Sementara wujud tajalli Tuhan yang paling sempurna adalah pada diri insan kamil, yaitu pada diri Nur Muhammad.

Persamaan pembahasan dalam jurnal tersebut dengan bahasan penelitian ini adalah sama-sama menganalisis tentang konsep insan kamil perspektif al-Jili. Perbedaan penelitian yang ditulis oleh Hasnawati dengan penelitian yang dilakukan oleh peneliti adalah Hasnawati tidak menyebutkan secara spesifik judul karya al-Jili yang merupakan buah pemikiran al-Jili berkenaan konsep insan kamil, sedangkan peneliti menyebutkan secara spesifik hasil karya al-Jili yang dianalisis, yakni Kitab al-Insan al-Kamil.

Berikutnya disertasi yang berjudul Pendidikan Karakter Melalui Pengasuhan Untuk Membentuk Manusia Seutuhnya hasil karya Devi Irena dari Institut Pemerintahan Dalam Negeri pada tahun 2015. Dalam disertasinya, Devi Irena menjelaskan bagaimana pendidikan karakter melalui pola pengasuhan dalam membentuk manusia seutuhnya. Devi Irena mencermati pendidikan di Indonesia cenderung menyiapkan anak cerdas secara intelektual, namun kurang memperhatikan aspek afektif secara optimal. Sehingga perlu mendapat perhatian secara khusus hal yang dianggapnya sebagai ketimpangan dengan menerapkan pendidikan karakter.

Persamaan pembahasan dalam disertasi tersebut dengan bahasan penelitian ini adalah sama-sama menganalisis manusia seutuhnya. Sedangkan perbedaan disertasi yang ditulis oleh Devi Irena adalah lebih fokus pada Pendidikan Karakter Melalui Pengasuhan Untuk Membentuk Manusia Seutuhnya. Sedangkan peneliti menganalisis Konsepsi Manusia Seutuhnya Dalam kitab al-Insan al-Kamil karya Abdul Karim al-Jili.

\section{Metode Penelitian}

Metode yang digunakan dalam penelitian ini adalah metode penelitian kualitatif non interaktif. Penelitian kualitatif non interaktif dikenal dengan penelitian analisis, yaitu penelitian yang mengkaji berdasarkan analisis dokumen. Penulis menghimpun, mengidentifikasi, menganalisis, mengadakan sintesis data, kemudian memberi interpretasi terhadap konsep. (Sukmadinata N. S., 2007) Jenis penelitian ini adalah studi 
kepustakaan (library research) yang dilakukan dengan bertumpu pada data kepustakaan tanpa diikuti dengan uji empirik. Studi pustaka di sini adalah studi teks yang seluruh substansinya diolah secara filosofis dan teoritis. (Muhadjir, 1996) Studi kepustakaan dalam penelitian ini adalah kitab al-Insan al-Kamil karya Abdul Karim al-Jili.

Selanjutnya, pendekatan yang digunakan dalam penelitian ini adalah pendekatan deskriptif, analisis kritis, dan analisis interpretasi yang merupakan analisis sistematis mengenai aksi sosial, melihat fakta sebagai sesuatu hal yang cair dan tidak kaku yang bermakna melalui observasi manusia secara terperinci dan langsung dalam latar ilmiah, supaya bisa memperoleh pemahaman dan interpretasi sebagai esensi dalam memahami makna sosial. (Newman, 2015)

Sumber data dalam penelitian ini dibagi dua, yakni sumber data primer dan sekunder. Sumber data primer dalam penelitian ini adalah Kitab al-Insan al-Kamil karya Abdul Karim al-Jili, baik yang berbahasa Arab maupun terjemahan dalam bahasa Indonesia. Selanjutnya yang kedua sumber data sekunder. Sumber data sekunder dalam penelitian ini berasal dari studi literatur berupa jurnal sebagaimana telah dikemukakan di atas yang digunakan untuk menunjang penelitian. Dalam seluruh proses penelitian, mulai dari awal hingga akhir, penulis memanfaatkan literatur yang relevan.

Sementara itu, teknik pengumpulan data dalam penelitian ini menggunakan teknik data kepustakaan berupa dokumentasi. Teknik dokumentasi adalah suatu teknik pengumpulan data dengan menghimpun dan menganalisis dokumen-dokumen, baik dokumen tertulis, gambar, maupun elektronik. Dokumen yang sudah dihimpun untuk selanjutnya dipilih yang sesuai dengan tujuan dan fokus masalah. (Sukmadinata N. S., 2007)

Metode analisis data dalam penelitian ini menggunakan analisis konten (content analysis) dan analisis historis (history analysis). (Zubair, 1990) Analisis konten merupakan sebuah teknik yang digunakan untuk memahami teks-teks dengan sambil merekonstruksi, sehingga memperoleh makna dan nuansa uraian yang disajikan secara khas. sedangkan analisis historis bertujuan untuk memahami konteks sejarah, meliputi riwayat hidup, pendidikan, latar belakang pemikiran, serta karya-karya yang dihasilkan. Dalam konteks ini penulis menelusuri, menggali, dan mengkaji rekam jejak Abdul Karim al-Jili pengarang kitab al-Insan al-Kamil.

\section{A. Biografi Singkat al-Jili}

\section{HaSil Dan PEMbahasan}

Nama lengkapnya adalah Abd al-Karim ibn Ibrahim al-Jili. Ia adalah seorang Sufi yang populer di Baghdad, yang digelari dengan Syekh dan Quthb al-Din, suatu gelar tertinggi dalam maqam Sufi. Al-Jili dikaitkan dengan tempat kelahirannya, yaitu Jilan; suatu daerah yang terletak di sebuah provinsi sebelah selatan Laut Kaspia. (Ya'qut, 1986) Menurut pengakuannya sendiri, ia adalah keturunan Syeikh 'Abd al-Qadir al-Jilani (470-561 H) 
pendiri Tarekat Qadiriyah, yakni turunan dari cucu perempuan Syeikh tersebut. (Nicholson, 1981) Al-Jili lahir pada awal Muharram tahun 767 H./1365 M. (Ali, 1997)

Meskipun al-Jili lahir di Baghdad, sejak usia kanak-kanak telah dibawa oleh orang tuanya berimigrasi ke Yaman (kota Zabid). Di kota Zabid inilah, al-Jili mendapatkan pendidikan sejak dini. Dalam tulisannya, ia mengatakan bahwa pada tahun $779 \mathrm{H}$. ia pernah mengikuti pelajaran dari Syeikh Syaraf al-Din Ismail ibn Ibrahim al-Jabarti (w. 806 H). (Ali, 1997)

Pada tahun $790 \mathrm{H}$ sebelum perjalanannya ke India, al-Jili menyempatkan singgah di Persia kemudian belajar bahasa Persia, hingga ia dapat menyelesaikan satu buah buku berjudul, Jannat-u al-Ma'arif wa Ghayat-u Murid wa al-Ma'arif. (Mustofa, 2007) Setelah itu ia berada di Kusyi, India dengan banyak melihat berbagai aliran tasawuf dan tarekat yang berkembang pesat, guna memperluas pengalaman dan pengetahuannya, meliputi tasawuf Ibn 'Arabi serta tarekat-tarekat seperti Syisytiyah yang didirikan oleh Mu'in alDin al-Syisyti (w. 623 H) di Asia Tengah, Suhrawardiyah yang didirikan oleh Abu Najib alSuhrawardi (w. 563 H) di Baghdad, dan Naqsyabandiyah yang didirikan oleh Baha' al-Din al-Naqsyaband (w. 791 H) di Bukhara. (Ahmad, 2018)

Kemudian pada akhir tahun $799 \mathrm{H}$ al-Jili berkunjung ke Makkah al-Mukarromah dalam rangka menunaikan ibadah Haji. Saat di Makkah ini pula ia tidak menyia-nyiakan waktunya, karena di waktu senggang ia pergunakan untuk bertukar fikiran dengan kalangan alim ulama. Hal yang mengindikasikan, bahwa al-Jili merupakan sosok yang gemar dan sangat mencintai ilmu pengetahuan. (Ahmad, 2018)

Pada tahun $803 \mathrm{H}$, al-Jili berkunjung ke Kairo, dan menyempatkan diri mengunjungi Universitas Al-Azhar serta bertemu dengan ulama-ulamanya. Di kota ini pula ia menyelesaikan penulisan bukunya yang berjudul, Ghunyah Arbab al-Sama' wa Kasyf alQina'an Wujud al-Istima. (Mustofa, 2007)

Selanjutnya di tahun yang sama ia berkunjung dan menetap di Gazzah, Palestina selama lebih kurang 2 (dua) tahun. Kunjungan ke Gazzah merupakan tahun terakhir dari perjalanannya ke Luar Zabid hingga akhirnya kembali lagi ke kota Zabid karena kerinduan yang begitu besar pada gurunya, al-Jabarti. Selang setahun kemudian, pada tahun $806 \mathrm{H}$ al-Jabarti meninggal dunia. 21 (dua puluh satu) tahun berselang, sekembali dari Gazzah, al-Jili menghabiskan waktu-waktunya dengan terus aktif menulis sampai akhir hayatnya dan wafat pada tahun 832 H./1428 M. (Ali, 1997)

Terkait jumlah dari karya-karya al-Jili, terdapat perbedaan di kalangan ilmuwan. Iqbal mengemukakan 3 (tiga) karya al-Jili, antara lain: al-Futuhat al-Makiyyah, yakni suatu ulasan atas karya Ibn 'Arabi, suatu komentar atas Basmalah, dan karyanya yang terkenal al-Insan al-Kamil. (Ahmad, 2018) Kemudian Haji Khalifah mencatat bahwa alJili telah menulis 6 (enam) buah kitab, yang selanjutnya dilengkapi oleh Ismail Pasya alBaghdadi yang mencatat 5 (lima) karya al-Jili di samping yang telah disebutkan oleh Haji Khalifah. Selain dari beberapa hasil penelitian di atas terkait karya al-Jili, Carl 
Brockelmann mencatat sebanyak 29 (dua puluh sembilan) judul karya al-Jili. Sedangkan Yunasril Ali mengemukakan sejumlah 34 (tiga puluh empat) kitab karya al-Jili. (Ahmad, 2018). Dari beberapa karya al-Jili, Kitab al-Insan al-Kamil fi Ma'rifat al-Awakhir wa alAwa'il adalah yang paling fenomenal dan menjadi rujukan dalam khazanah dunia tasawuf, khususnya terkait dengan bagaimana menyelami dan memahami konteks manusia sempurna (manusia seutuhnya).

Berikut secara sederhana dapat dideskripsikan kitab al-Insan al-Kamil yang terdiri atas 64 bab karya Abdul Karim al-Jili: Bab 1 Dzat, Bab 2 Isim (Nama) Mutlak, Bab 3 Sifat Mutlak, Bab 4 Uluhiyah (Ketuhanan), Bab 5 Ahadiyah (ke-Esa-an), Bab 6 Wahidiyah (keTunggal-an), Bab 7 Rahmaniyah (ke-Pemurah-an), Bab 8 Rububiyah (ke-Pengatur-an), Bab 9 Kabut, Bab 10 at-Tanzih (Transendensi), Bab 11 at-Tasybih (Antropomorfisme), Bab 12 Manifestasi Perbuatan al-Haq, Bab 13 Manifestasi Nama-Nama al-Haq, Bab 14 Manifestasi Sifat-Sifat al-Haq, Bab 15 Sentra Manifestasi Inti (Dzat), Bab 16 al-Hayah (Maha Hidup), Bab 17 al-'Ilm (Maha Berpengetahuan), Bab 18 al-Iradah (Maha Berkehendak), Bab 19 al-Qudrah (Maha Kuasa), Bab 20 al-Kalaam (Maha Berbicara), Bab 21 as-Sam'u (Maha Mendengar), Bab 22 al-Bashar (Maha Melihat), Bab 23 al-Jamaal (Keindahan), Bab 24 al-Jalaal (Keperkasaan), Bab 25 al-Kamaal (Kesempurnaan), Bab 26 Hawiyah (Ke-Dia-an), Bab 27 Inniyah (ke-Aku-an), Bab 28 Azali (Tidak Berawal), Bab 29 Abadi (Selama-lamanya), Bab 30 al-Qidam (Eternitas), Bab 31 Hari-Hari Allah SWT, Bab 32 Bunyi Lonceng, Bab 33 Umm al-Kitab (Induk Kitab), Bab 34 Al-Qur'ān, Bab 35 alFurqan, Bab 36 Taurat, Bab 37 Zabur, Bab 38 Injil, Bab 39 Perihal Turunnya al-Haq ke Langit Dunia Setiap Malam, di Sepertiga Akhir Malam, Bab 40 Fatihah (Pembukaan) Kitab, Bab 41Tentang Bukit (Thur), Kitab Yang Ditulis, Pada Lembaran Yang Terbuka, Baitul Ma'mur, Atap Yang Ditinggikan, Laut Yang Di Dalam Tanahnya Ada Api, Bab 42 Bantal Yang Tinggi, Bab 43 Tikar Dan Mahkota, Bab 44 Dua Sandal Dan Dua Kaki, Bab 45 Arsy (Singgasana), Bab 46 Kursi, Bab 47 Qolam (Pena) Tertinggi, Bab 48 Lauhul Mahfudz, Bab 49 Sidratul Muntaha, Bab 50 Ruh Qudus, Bab 51 Malaikat Yang Diberi Nama Ruh, Bab 52 Hati Dan Asal Penciptaan Israfil Dari Cahaya Muhammad SAW, Bab 53 Akal Pertama dan Asal Penciptaan Jibril Dari Cahaya Muhammad SAW, Bab 54 Estimasi dan Asal Penciptaan 'Izrail Dari Cahaya Muhammad SAW, Bab 55 Cita-cita dan Asal Penciptaan Mikail Dari Cahaya Muhammad SAW, Bab 56 Logika Dan Asal Penciptaan Para Malaikat Dari Cahaya Muhammad SAW, Bab 57 Imajinasi (Hayal) Benda Pertama Semesta Alam, Bab 58 Shurah (Citra) Muhammad SAW, Adalah Cahaya Asal Penciptaan Surga dan Neraka Yang Melahirkan Nikmat dan Siksa, Bab 59 Nafsu Dan Asal Penciptaan Iblis Serta Para Pengikutnya Dari Setan Dan Manusia, Bab 60 Insan Kamil (Manusia Sempurna) Adalah Muhammad SAW Citra al-Haq Dan Makhluk, Bab 61 Tanda-Tanda Kiamat, Ingat Kematian, Barzah, Kiamat Hisab, Timbangan, Shirat (Titian), Neraka, Surga, A'rāf, Katsiib, Bab 62 Tujuh Langit dan Apa Yang Ada Di Atasnya, Tujuh Bumi dan Apa Yang Ada Di Bawahnya, Tujuh Lautan dan Keajaiban-Keajaibannya, Serta Penghuni Yang Ada Di 
Dalamnya, Bab 63 Akidah Semua Agama Dan Ritual Ibadah Serta Nuqtah (Titik) Segala Haal dan Maqomat, Bab 64 Rahasia Ibadah: Berdasarkan Keterangan Rasul Muhammad SAW.

\section{B. Manusia Seutuhnya Perspektif Abdul Karim al-Jili}

Mengawali pembahasan kitab al-Insan al-Kamil karya Abdul Karim al-Jili, maka perlu kiranya terlebih dahulu memahami secara garis besar makna atau definisi tasawuf, sebab bahasan kitab al-Insan al-Kamil berada dalam ruang lingkup tasawuf, terkait dengan rohani, suasana kebatinan, kejiwaan seseorang dalam upaya mendekatkan diri kepada Allah SWT dengan jalan membersihkan atau mesucikan jiwa.

Ma'ruf al-Kurkhi mengemukakan bahwa, tasawuf merupakan berpegang pada apa yang hakiki dan menjauhi sifat tamak terhadap apa yang ada di tangan manusia. Sedangkan menurut Ahmad al-Jariri, tasawuf adalah keluar dari budi perangai yang tercela dan masuk kepada budi perangai yang terpuji. (al-Naisaburi, 434 H)

Sementara Ahmad Rifa'i mengemukakan bahwa, tasawuf adalah ilmu yang membahas tentang tingkah laku manusia baik yang berupa amalan terpuji maupun amalan tercela agar hatinya benar dan lurus dalam menuju Allah SWT, sehingga ia dapat berada dekat, sedekat-dekatnya di hadirat Allah SWT. (Rifa'i, 1266 H/1851 M)

Imam al-Ghozali menyatakan bahwa tasawuf memiliki dua pilar, yaitu istiqamah bersama Allah dan harmonis dengan makhluk-Nya. Dengan demikian siapa saja yang istiqamah bersama Allah SWT, berakhlak baik terhadap orang lain, dan bergaul dengan mereka dengan santun, maka ia adalah seorang Sufi. (Al-Ghazali, 2005)

Tasawuf sebagai suatu upaya mendekatkan diri kepada Allah dengan jalan pensucian jiwa, maka setidaknya ada 3 (tiga) unsur di dalamnya, antara lain:

1. Takhalli; membuang/menghilangkan sifat-sifat kotor dalam diri.

2. Tahalli; memasukkan/mengisi sifat-sifat baik/terpuji dalam diri.

3. Tajalli; terbukanya tabir yang menghalangi hamba dengan Allah SWT, sehingga hamba menyaksikan tanda-tanda kekuasaan dan keagungan-Nya. Dengan kata lain, lenyapnya hijab dari ranah sifat kemanusiaan, ketika nampak wajah Allah. (Suyuti, 1996)

Lebih lanjut, tasawuf diklasifikasikan menjadi 3 (tiga), yaitu: tasawuf falsafi, tasawuf amali, dan tasawuf akhlaqi. (Kholifah, 2018) Insan kamil al-Jili dalam bahasan ini termasuk dalam kategori tasawuf falsafi. Tasawuf falsafi adalah konsep mengenal Tuhan (ma'rifat) dengan pendekatan rasio (filsafat) hingga menuju ke tingkatan yang lebih tinggi, bukan hanya mengenal Tuhan saja (ma 'rifatullah), melainkan lebih dari itu yaitu wahdat al-wujud atau yang berarti kesatuan wujud, bisa dikatakan jika tasawuf falsafi ini merupakan tasawuf yang di dalamnya terdapat pemikiran-pemikiran filsafat, sebab bahasan dan kajian berfokus pada ranah filsafat. (al-Taftazani, 2008) 
Dari beberapa kitab karya Abdul Karim al-Jili, al-Insan al-Kamil (Al-Insan al-Kamil fi Ma'rifat al-Awakhir wa al-Awa'il) merupakan kitab yang paling fenomenal, fokus kajiannya adalah tentang insan kamil. Insan berarti manusia, dan Kamil berarti sempurna. Jadi Insan Kamil adalah Manusia Sempurna (The Perfect Man). Untuk selanjutnya dalam kaitan penelitian ini, penulis menggunakan diksi Manusia Seutuhnya (asal kata utuh) yang menjadi padanan kata dari Insan Kamil, atau Manusia Sempurna.

Mengkaji konsep insan kamil karya al-Jili (767 H/1365 M- 832 H/1428 M) tentu tidak dapat dilepaskan dari kajian pemikiran Syaikh al-Akbar Muhyi al-Din Ibn 'Arabi (563 H/1165 M-638 H/1240 M) yang juga membawa ide lebih awal tentang insan kamil, dengan beberapa karyanya seperti al-Basyar al-Kamil, al-Kummal dan lainnya yang tertuang dalam kitab al-Futuhat al-Makkiyyah yang ditulis pada tahun $1201 \mathrm{H}$, telah banyak memberi pengaruh. Meski beberapa sarjana menganggap bahwa konsep insan kamil al-Jili berbeda dengan Ibn 'Arabi, namun sebagian yang lain beranggapan bahwa konsep insan kamil al-Jili tidak lebih sebagai penerus konsep Ibn 'Arabi; andilnya lebih memperjelas dan mensistemisasi. (Ahmad, 2018)

Mencermati lebih jauh masa kehidupan al-Jili dengan Ibn 'Arabi tentu banyak terdapat perbedaan, antara lain: rentang jarak kehidupan yang begitu panjang lebih kurang 2 (dua) abad. Dalam kurun waktu tersebut tentu banyak terdapat perbedaan mengenai kondisi sosial, politik, ekonomi, budaya, dll. Sehingga dengan itu dapat diasumsikan bahwa faktor-faktor tersebut sangat kuat mempengaruhi perbedaan konsep insan kamil antara al-Jili dengan Ibn 'Arabi.

Secara sosio kultural kehidupan al-Jili lebih banyak dipengaruhi oleh budaya Yaman yang pada saat itu dikuasai oleh Bani Rasul yang menggantikan kekuasaan Daulah Ayyubiyah dari Mesir, di mana pengetahuan keagamaan termasuk juga tasawuf bercorak sunni lebih berkembang. Hal berbeda dengan yang dialami Ibn 'Arabi di masanya ketika di belahan barat dunia Islam pemikiran filsafat dan ilmu pengetahuan berkembang dengan pesat dan mencapai masa keemasannya. (Hasnawati, 2016)

Atas dasar itu, kelebihan yang diperoleh al-Jili telah melahirkan satu metodologi lebih kompleks yang mengkombinasi keduanya, yakni corak tasawuf falsafi dengan corak teologi sunni. Dan tentunya, dengan demikian insan kamil karya al-Jili ini dipandang lebih komprehensif dari yang pernah ditulis oleh Ibn 'Arabi.

Insan kamil (manusia sempurna) merupakan ajaran tasawuf al-Jili yang terpenting, yang merupakan pengembangan dari konsep tasawuf Ibn 'Arabi, yaitu wahdat al-wujud, bahwa alam ini diciptakan Tuhan karena Dia ingin memperlihatkan diri-Nya di luar diriNya. Alam adalah cermin bagi Tuhan pada saat Dia ingin melihat diri-Nya, sebab pada alam terdapat sifat-sifat-Nya. Akan tetapi, bentuk dari alam yang paling sempurna adalah terdapat pada diri manusia sempurna (insan kamil). Pemikiran ini yang melahirkan faham wahdat al-wujud. (Hasnawati, 2016) 
Pandangan mengenai wahdat al-wujud tidak dimaknai secara leterlek/tekstual bersatunya dua dzat yang berbeda ke dalam satu wujud, melainkan suatu makna di mana seorang sufi yang sudah mencapai ketinggian derajat insan kamil akan merasakan esensi dari realitas absolut, wujud hakiki itu hanya dimiliki Tuhan. Selain Tuhan, maka disebut realitas fana. Sampai pada akhirnya seorang sufi benar-benar merasakan bahwa yang ada hanya Tuhan, yang lain tidak ada, termasuk dirinya.

Ahmad Faiq Nur, mengemukakan bahwa mengungkapkan pemahaman tentang Tuhan yang Maha tak terbatas dengan menggunakan bahasa manusia yang terbatas memanglah tidak mudah. Kerap kali para sufi menggambarkan hubungan antara Tuhan dengan makhluk dengan ungkapan-ungkapan yang kadangkala disalahpahami oleh sebagian orang. (Nur, 2020)

Dalam mendeskripsikan kedekatan dan rasa cinta yang begitu besar seorang sufi kepada Tuhannya, maka bahasa yang digunakan turut memberikan ekspresi, apa yang tengah dirasakan dan dialami seorang sufi ketika merasakan nuansa kebatinan yang sedemikian dalam kepada Tuhannya. Bahkan, jika boleh dikatakan, hampir tidak ada kata-kata yang mampu merepresentasikan perasaan dan melukiskannya. Oleh sebab itu pilihan kalimat yang digunakan Ibn 'Arabi untuk hal-hal semacam ini senantiasa mengandung makna metafora.

Jika isi (ideas), lebih besar dari wadah (containers), atau jika ide lebih besar dari ekspresi bahasa, sehingga bahasa tak mampu lagi mengungkapkan suatu ide untuk dipahami penerima secara menyeluruh, maka bahasa penggantilah yang digunakannya. Di sinilah ungkapan-ungkapan metaforis mengambil peranannya. (Nur, 2020) Dengan alasan-alasan tersebut, maka penggunaan kalimat-kalimat metafora dianggap lebih mengena kepada maksud yang sesungguhnya dialami dan dirasakan oleh seorang sufi. Sedangkan al-Jili, dalam pembahasan terkait hal seperti ini selalu memberikan "warning" dengan menambahkan keterangan dan memberikan tekanan kalimat secara eksplisit, bahwa sungguhpun manusia mampu berhias dengan nama dan sifat-sifat Tuhan, ia tetap tidak bisa menyamai nama dan sifat-sifat-Nya. Manusia adalah manusia, dan Tuhan adalah Tuhan. Hal ini sesuai dengan firman Allah SWT dalam Al-Qur'ān surat Ash-Shura [42] ayat 11:

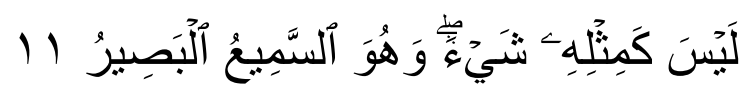

Tidak ada sesuatupun yang serupa dengan Dia, dan Dialah yang Maha Mendengar dan Melihat.

Insan kamil dipandang sebagai orang yang mendapat pengetahuan esoterik (karunia) yang dikenal dengan pengetahuan rahasia ('ilm al-Asrār), namun dari segi mental spiritual ia memiliki kualitas-kualitas yang jauh lebih tinggi dan sempurna dibanding manusia lainnya. Jika seseorang telah mampu mengosongkan aql (nalar) dan qalb-nya (naluri) dari egoisme, keangkuhan, dan sifat buruk lainnya dengan keikhlasan yang total, maka Tuhan hadir membukakan pintu kebenaran dan ia masuk ke dalamnya, memasuki kebenaran itu, dan ketika ia keluar, maka ia menjadi dan menyatu dengan kebenaran yang telah dimasukinya. (Asy'arie, 2002) 
Insan kamil merupakan duplikasi sifat-sifat Tuhan yang ada padanya. Dan untuk bisa sampai pada derajat insan kamil, prasyarat yang harus dipenuhi adalah proses pensucian hati, sebab dengan jiwa yang suci akan mampu mengadakan kontak dengan yang Mutlak. Dan inilah yang dikatakan derajat spiritual yang paling tinggi, sebuah cara hidup yang mendekati kemiripan dengan Tuhan. Sebagaimana dikemukakan Ahmad, dkk, bahwa manusia merupakan bayang-bayang Tuhan sekaligus makhluk yang paling sanggup menyerupai Tuhan, karena ia memiliki ruh, punya lokus atau 'arsy Tuhan. (Ahmad, 2018) Hal ini sesuai dengan firman Allah SWT dalam Al-Qur'ān surat Al-Hijr [16] ayat 29:

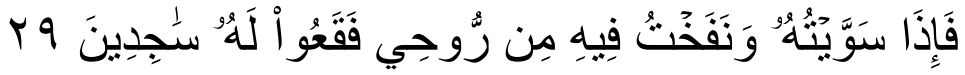

Maka apabila Aku telah menyempurnakan kejadiannya, dan telah meniupkan ke dalamnya ruh (ciptaan)-Ku, maka tunduklah kamu kepadanya dengan bersujud.

\section{Realitas Mutlak}

Di dalam kesendirian-Nya yang gaib itu, esensi mutlak tidak dapat difahami dan tidak ada kata-kata yang dapat menggambarkan-Nya, karena indera, pemikiran, akal, dan pengertian mempunyai kemampuan yang fana dan tidak pasti, hal yang tidak pasti akan menghasilkan ketidakpastian pula. Karena itu, tidak mungkin manusia yang serba terbatas akan dapat mengetahui dzat Mutlak itu secara pasti. Al-Jili mengatakan, "Sesungguhnya saya telah memikirkan-Nya, namun bersama itu pula saya bertambah tidak tahu tentang-Nya." (Al-Jili, 1975)

Hal yang mendasari keyakinan al-Jili, bahwa alam ini bukanlah diciptakan dari bahan yang telah ada, akan tetapi diciptakan dari ketiadaan (creatio ex nihilio) di dalam ilmuNya, sebagaimana yang diungkapkannya;

"Allah SWT memiliki wujud yang pertama karena kebebasan-Nya yang mandiri, sementara makhluk memiliki wujud yang kedua karena ketergantungannya kepada Allah. Dalam wujud yang pertama makhluk ini tidak ada, lalu Tuhan menciptakannya secara ilahiah dari ketiadaan sejati di dalam ilmu-Nya, kemudian dijelmakan-Nya dari 'alam 'ilmi (lingkup pengetahuan Ilahi) ke alam nyata, dengan kodrat-Nya; dan penciptaan-Nya akan makhluk adalah penciptaan dari tidak ada, lalu ada dalam imu Tuhan, dan kemudian ada dalam alam nyata." (Al-Jili, 1975)

Dari ungkapan al-Jili di atas, maka terlihat perbedaan antara al-Jili dan Ibn 'Arabi. Ibn 'Arabi mengatakan bahwa alam ini bukan diciptakan dari sesuatu yang tidak ada melainkan dari sesuatu yang telah ada, yakni yang terdapat dalam ilmu Tuhan. Wujud yang ada dalam ilmu Tuhan itulah yang kemudian muncul sebagai alam nyata. Pandangan Ibn 'Arabi tersebut mendapat bantahan dari al-Jili yang mengatakan bahwa, jika alam ini berasal dari sesuatu yang ada dalam ilmu Tuhan, maka menurut al-Jili Tuhan tidak memiliki kekuasaan dalam menciptakan alam, Tuhan hanya bisa menciptakan dari sesuatu yang telah ada saja. (Kesuma, 2018) 
Hal demikian menurut al-Jili sangat bertentangan dengan ke-Maha Kuasaan Tuhan dan mustahil bagi Tuhan. Jika ditinjau lebih jauh, maka akan muncul pertanyaan sebagai berikut: jika alam ini adalah wadah tajalli Tuhan, maka apakah kemudian alam identik dengan Tuhan? Untuk menjawab pertanyaan tersebut, al-Jili mengumpamakan hal demikian seperti air dan es. (Yusuf Zaidan, 1988) Tuhan menurut al-Jili diumpamakan seperti air dan alam diumpamakan seperti es. Akan tetapi es sebenarnya atau pada hakikatnya adalah air itu sendiri. (Al-Jili, 1975)

\section{Nur Muhammad}

Konsep tasawuf al-jili beranjak dari pandangan tentang adanya tajalli Tuhan dalam benda-benda, baik benda mati maupun benda hidup. Bentuk Tuhan yang lebih sempurna dilihat pada benda yang hidup daripada benda mati. Oleh karena itu, Tuhan menampakkan diri dan beredar dalam segala yang wujud (aflak al-wujud) dari awal sampai akhir. Di antara banyaknya benda-benda tersebut, ada sosok benda hidup yang merupakan bentuk wujud Tuhan yang paling sempurna, yaitu manusia. Tajalli Tuhan yang lebih sempurna terdapat pada diri manusia. (Hasnawati, 2016) Untuk selanjutnya al-Jili merumuskan manusia sempurna (insan kamil) dengan merujuk pada diri Nabi Muhammad SAW, sebagai sebuah contoh manusia ideal.

Menurut al-Jili, Nabi Muhammad SAW adalah Al-Insan al-Kamil, karena mempunyai sifat-sifat al-Haq (Tuhan) dan al-Khalq (makhluk) sekaligus. Hal ini karena sifat dan nama tersebut tidak memiliki tempat berwujud, melainkan pada insan kamil. Dan sesungguhnya al-Insan al-Kamil itu adalah Nur (ruh/cahaya) Muhammad SAW. yang diciptakan dalam diri nabi-nabi, sejak dari Nabi Adam a.s. sampai Nabi Muhammad SAW, wali-wali, serta orang-orang shaleh. Al-Insan al-Kamil digambarkan dan diperumpamakan hubungan Tuhan dengan insan kamil bagaikan cermin. Seseorang tidak dapat melihat bentuk dirinya kecuali melalui cermin tersebut. (Toriquddin., 2008)

Nur Ilahi kemudian dikenal sebagai Nur Muhammad oleh kalangan Sufi, di samping terdapat dalam diri Nabi Muhammad SAW, juga dipancarkan Allah SWT ke dalam diri Nabi Adam a.s. Al-Jili dengan karya monumentalnya yang berjudul al-Insan al-Kamil fi Ma'rifat al-Awakhir wa al-Awa'il (Manusia Sempurna dalam Konsep Pengetahuan tentang Misteri yang Pertama dan yang Terakhir) mengawali pembicaraannya dengan mengidentifikasi insan kamil dengan dua pengertian:

Pertama, insan kamil dalam pengertian konsep pengetahuan mengenai manusia yang sempurna. Dalam pengertian demikian, insan kamil terkait dengan pandangan mengenai sesuatu yang dianggap mutlak, yaitu Tuhan. Yang Mutlak tersebut dianggap mempunyai sifat-sifat tertentu, yakni yang baik dan sempurna. Sifat sempurna inilah yang patut ditiru oleh manusia. Seseorang yang makin memiripkan diri pada sifat sempurna dari Yang Mutlak tersebut, maka makin sempurnalah dirinya.

Kedua, insan kamil terkait dengan jati diri yang mengidealkan kesatuan nama serta sifat-sifat Tuhan ke dalam hakikat atau esensi dirinya. Dalam pengertian ini, nama 
esensial dan sifat-sifat Ilahi tersebut pada dasarnya juga menjadi milik manusia sempurna oleh adanya hak fundamental, yaitu sebagai suatu keniscayaan yang inheren dalam esensi dirinya. Hal itu dinyatakan dalam ungkapan yang sering terdengar, yaitu Tuhan berfungsi sebagai cermin bagi manusia dan manusia menjadi cermin bagi Tuhan untuk melihat diri-Nya.

\section{Proses Munculnya Insan Kamil}

Menurut al-Jili, tajalli Tuhan berlangsung secara terus menerus pada alam semesta dan terdiri atas lima martabat, (al-Jili, tt) yakni:

Pertama, Uluhiyah; merupakan tahap tertinggi dalam proses tajalli Tuhan. Uluhiyah merupakan esensi dzat primordial dan merupakan wujud primer yang menjadi sumber segala yang ada dan tidak ada. Nama yang digunakan dalam peringkat ini adalah "Allah," karena dalam pandangan al-Jili sendiri, sebutan "Allah" merupakan nama tertinggi bagi Tuhan di atas nama-Nya al-Ahad yang digunakan oleh Ibn 'Arabi sebagai tingkat tajalli tertinggi Tuhan (Ahadiyah).

Kedua, Ahadiyah; tahap ini muncul dari tahap sebelumnya (uluhiyah), di mana tingkatan ini merupakan sebutan dari dzat murni (al-Dzat al-Sadzi) yang tidak memiliki nama dan sifat, dan tahap ini tidak bisa dicapai oleh pengetahuan manusia karena tidak ada kalimat dan kata-kata yang dapat menggambarkan-Nya. Dan dalam tahap ini menurut al-Jili mengalami tiga penurunan (tanazzul):

1) Ahadiyah, Dzat Mutlak menyadari ke-Esa-an diri-Nya.

2) Huwiyah, kesadaran Dzat Mutlak terhadap ke-Esa-an-Nya yang gaib.

3) Aniyah, Dzat Mutlak menyadari diri-Nya sebagai Kebenaran.

Ketiga, Wahidiyah; di mana pada tahap ini dzat Tuhan menampakkan diri-Nya pada sifat dan asma' (nama), tetapi sifat dan asma' itu sendiri masih identik dengan dzat Tuhan karena dzat ini pun masih berupa potensi-potensi dan belum mampu mengaktual secara keseluruhan.

Keempat, Rahmaniyah; pada tahap ini Tuhan bertajalli pada realitas asma' dan sifat, dan dengan kalimat "kun" (jadilah), muncullah realitas-realitas potensial yang terdapat dalam tahap wahidiyah tadi menjadi wujud yang aktual, yakni alam semesta. Tetapi aktualitas ini masih bersifat universal, karena bersamaan dengan proses penciptaan alam secara keseluruhan.

Kelima, Rububiyah; dalam tahap ini Tuhan bertajalli pada alam semesta yang sudah mengalami partikularisasi (terbagi-bagi) dan sudah beragam, khususnya pada diri manusia (sebagai makhluk yang terbatas) untuk memanifestasikan diri-Nya yang tidak terbatas itu dengan menunjukkan citra-Nya dalam diri manusia, dan citra Tuhan yang paling utuh bisa ditemukan dalam diri seorang insan kamil. Adapun tajalli ini akan mengalami pantulan yang akan berbalik arah ke arah semula (dari dzat sampai perbuatan, kemudian berbalik dan memantul dari perbuatan menuju dzat); pertama 
tajalli perbuatan (tajalli al-Af'al), kedua tajalli nama-nama (tajalli al-Asma'), ketiga tajalli sifat-sifat (tajalli ash-Shifat), keempat tajalli dzat (tajalli ad-Dzat).

\section{Maqam}

Al-Jili dengan filsafat insan kamilnya, merumuskan beberapa maqam yang harus dilalui seorang sufi, yang menurut istilahnya ia sebut al-Martabah (jenjang atau tingkat). (Al-Jili, 1975) Tingkat-tingkat itu adalah:

Pertama, Islam yang didasarkan pada lima pokok atau rukun dalam pemahaman kaum sufi tidak hanya dilakukan ritual saja, tetapi harus difahami dan dirasakan lebih mendalam. Dalam mencapai derajat insan kamil, seseorang harus memulainya dengan melakukan pengalaman rukun Islam secara baik dan dilakukan secara lahir dan batin. Dari segi lahir hendaknya manusia dalam melakukan amalan-amalan tersebut dilakukan dengan merujuk pada ketentuan syari'at, sementara dari segi batin adalah dengan melakukan penghayatan terhadap amalan-amalan yang dilakukan tersebut. (Yusuf Zaidan, 1988)

Kedua, Iman yakni membenarkan dengan sepenuh keyakinan akan rukun iman, dan melaksanakan dasar-dasar Islam. Iman merupakan tangga pertama mengungkap tabir alam gaib serta alat yang membantu seseorang mencapai tingkat atau maqam yang lebih tinggi. Setelah sufi mengamalkan dan menghayati rukun Islam, kemudian meyakini rukun Iman secara mantap seperti meyakini sesuatu yang ditangkap oleh panca indra. Karena Iman menurut al-Jili adalah cahaya dari cahaya Ilahi, melalui cahaya tersebut sufi dapat melihat sesuatu yang tidak terlihat oleh mata kepala. (Yusuf Zaidan, 1988)

Ketiga, ash-Shaleh (kesalehan), yakni dengan maqam ini seorang sufi mencapai tingkat ibadah yang terus-menerus kepada Allah SWT dengan penuh perasaan khauf (takut) dan raja' (pengharapan). Tujuan ibadah pada maqam ini adalah mencapai nuqtah Ilahiah pada lubuk hati sang hamba, sehingga ketika mencapai kasyaf, ia akan menta'ati syariat Tuhan dengan baik.

Keempat, Ihsan, yakni dengan maqam ini menunjukkan bahwa seorang sufi telah mencapai tingkat menyaksikan efek (atsar) nama dan sifat Tuhan, sehingga dalam ibadahnya, ia merasa seakan-akan berada di hadapan-Nya. Persyaratan yang harus ditempuh pada maqam ini adalah sikap istiqamah dalam taubat, inabah, zuhud, tawakkal, tafwidh, ridha', dan ikhlas. (Yusuf Zaidan, 1988) Pada maqam tawakkal, sufi sebenarnya telah masuk pada tingkat awal dari tajalli Tuhan yakni tajalli al-Af'al. Pada tingkatan ini seorang sufi telah disinari oleh perbuatan Tuhan.

Kelima, asy-Syahadah (penyaksian), seorang sufi dalam maqam ini telah mencapai iradah yang bercirikan; mahabbah kepada Tuhan tanpa pamrih, mengingat-Nya secara terus-menerus, dan meninggalkan hal-hal yang menjadi keinginan pribadi. asy-Syahadah terbagi ke dalam dua tingkatan, yaitu mencapai mahabbah kepada Tuhan tanpa pamrih. Ini adalah tingkat yang paling rendah, dan menyaksikan Tuhan pada semua makhluk-Nya secara 'ainul yaqin. Ini adalah yang paling tinggi. 
Keenam, ash-Shiddiqiyah (kebenaran), istilah ini menggambarkan tingkat pencapaian hakikat yang ma'rifat yang diperoleh secara bertahap dari ilmu al-Yaqin, 'ayn al-Yaqin, sampai haq al-Yaqin. Menurut al-Jili, seorang sufi yang telah mencapai derajat shiddiq akan menyaksikan hal-hal yang gaib, kemudian melihat rahasia-rahasia Tuhan, sehingga mengetahui hakikat diri-Nya.

Dalam tingkatan ini, sufi mencapai tingkat ma'rifat dalam tiga bentuk: pertama; 'ilm al-Yaqin, kedua, 'ayn al-Yaqin, ketiga, haq al-Yaqin. Pada tingkat yang pertama, sufi disinari oleh asma Tuhan; pada tingkat kedua, sufi disinari oleh sifat-sifat Tuhan; pada tingkat ketiga, sufi disinari oleh dzat Tuhan. Dengan demikian, diri sufi mengalami fana' dalam asma', sifat, dan dzat Tuhan. (Yusuf Zaidan, 1988)

Ketujuh, Qurbah. Maqam ini merupakan maqam yang memungkinkan seseorang dapat menampakkan diri dalam sifat dan nama yang mendekati sifat dan nama Tuhan. Pada fase ini seorang sufi bisa dikatakan telah mencapai derajat sebagai insan kamil. (Yusuf Zaidan, 1988) Pada tahapan ini, ada empat pendekatan seorang sufi kepada Tuhan, yaitu:

1) Al-Khullah, yakni sebuah persahabatan dengan Tuhan, sehingga Tuhan dikenal secara intim. Dengan demikian sufi senantiasa berbuat sesuai dengan apa yang dikehendaki-Nya.

2) $A l-H u b b$, yaitu sebuah percintaan sufi dan Tuhannya, sehingga yang satu merasakan apa yang dirasakan oleh yang lainnya.

3) Al-Khiram, adalah sebuah pencitraan Tuhan secara utuh terhadap seorang sufi, tetapi kesempurnaan Tuhan tidak tercapai oleh sufi secara keseluruhan, karena kesempurnaan-Nya tidak terbatas.

4) Al-Ubudiyah, adalah sebuah penghambaan seorang sufi terhadap Tuhannya, karena bagaimana pun ia tidak akan dapat menjadi Tuhan.

Terkait dengan itu, satu hal yang perlu difahami, bahwa al-Jili mengatakan "mengetahui dzat yang Maha Tinggi itu secara kasyaf Ilahi, yaitu kamu di hadapan-Nya dan Dia di hadapanmu tanpa hulul dan ittihad. Sebab hamba adalah hamba dan Tuhan adalah Tuhan. Oleh sebab itu, tidaklah mungkin hamba menjadi Tuhan atau sebaliknya." Dengan pernyataan ini, kita fahami bahwa sungguhpun manusia mampu berhias dengan nama dan sifat Tuhan, namun ia tetap tidak bisa menyamai nama dan sifat-sifat-Nya.

\section{Klasifikasi/tingkatan}

Lebih lanjut al-Jili menjelaskan, meskipun manusia telah mencapai derajat sebagai insan kamil, akan tetapi ia tidak akan dapat menyamai kesempurnaan yang telah dicapai oleh Nabi Muhammad SAW, sebab Nabi Muhammad SAW adalah puncak dari kesempurnaan dan ialah yang telah mencapai insan kamil secara hakiki. Penjelasan tersebut dilatarbelakangi oleh adanya pembagian tingkatan yang dilakukan oleh al-Jili yang membagi insan kamil dalam tiga tingkatan: (Kesuma, 2018) 
Pertama, al-Bidayah atau tingkat permulaan, pada tingkat ini insan kamil mulai dapat merealisasikan asma dan sifat-sifat Ilahi pada dirinya.

Kedua, at-Tawassuth atau tingkat menengah. Pada tingkat ini insan kamil sebagai orbit kehalusan sifat kemanusiaan yang terkait dengan realitas kasih Tuhan. Pada tingkat ini hal-hal yang gaib dapat dibukakan oleh Tuhan padanya.

Ketiga, al-Khitam atau tingkat terakhir. Pada tingkat ini insan kamil telah dapat merealisasikan citra Tuhan secara utuh. Pada tingkat ini insan kamil dapat mengetahui rahasia takdir.

Setiap manusia yang berupaya mencapai tingkatan insan kamil, tidak bisa lepas dari tingkatan yang pertama secara hierarkis. Insan kamil yang diperoleh kalangan sufi, tidak berbeda dengan tingkatan yang diperoleh Nabi Muhammad SAW, perbedaannya hanya pada tingkat superlatif (paling). (Hasnawati, 2016)

\section{Nabi Muhammad SAW Insan Kamil}

Dengan merujuk pada diri Nabi Muhammad SAW sebagai insan kamil, maka yang terpenting harus diketahui adalah sifat-sifat utama yang dimilikinya meliputi Shiddiq (jujur/benar), Tabligh (menyampaikan kebenaran), Amanah (dapat dipercaya), dan Fathonah (cerdas/bijak) serta memahami perilakunya dalam kehidupan sehari-hari. Dalam kaitan ini Al-Qur'ān dan Hadits (Sunnah) merupakan dua sumber utama ajaran Islam, memberikan informasi yang lengkap tentang semua sifat dan perilaku Nabi Muhammad SAW. Hal ini sesuai dengan firman Allah SWT dalam Al-Qur'ān surat Al-Ahzab [33] ayat 21:

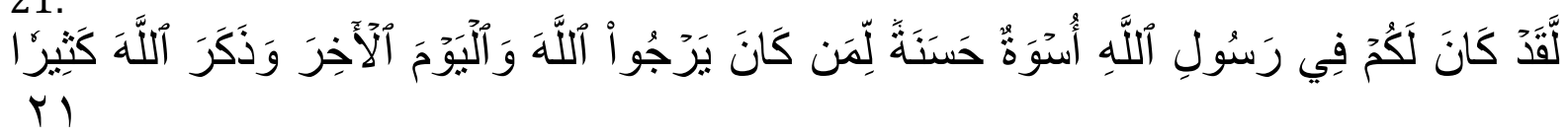

Sesungguhnya telah ada pada (diri) Rasulullah SAW itu suri teladan yang baik bagimu (yaitu) bagi orang yang mengharap (rahmat) Allah SWT dan (kedatangan) hari kiamat dan dia banyak menyebut Allah SWT.

Keutamaan pada diri Nabi Muhammad SAW tergambar jelas dalam sifat dan prilakunya yang mulia. Hal ini sesuai dengan firman Allah SWT dalam Al-Qur'ān surat Al-Qolam [68] ayat 4:

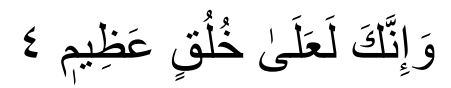

Dan sesungguhnya kamu (Muhammad) benar-benar berbudi pekerti yang agung.

Sabda Nabi Muhammad SAW yang diriwayatkan oleh Ahmad:

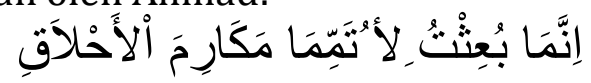

Aku (Nabi Muhammad SAW) diutus untuk menyempurnakan akhlaq.

Diutusnya Nabi Muhammad SAW bukan hanya untuk suatu golongan atau bangsa tertentu, melainkan untuk seluruh semesta alam (rahmatan lil'alamin). Hal ini sesuai dengan Al-Qur'ān surat Al-Anbiya [21] ayat 107: 
$1 \cdot V$

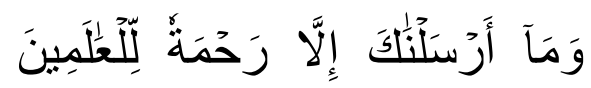

Dan tidaklah Aku (Alloh SWT) mengutus engkau (Muhammad SAW), kecuali menjadi rahmat bagi semesta alam.

Adapun hasil analisis penulis tentang Konsepsi Manusia Seutuhnya dalam Kitab alInsan al-Kamil karya Abdul Karim al-Jili antara lain:

Pertama, insan kamil (manusia sempurna) merupakan ajaran tasawuf al-Jili bercorak falsafi bernuansa teologi sunni, pengembangan dari konsep tasawuf Ibn 'Arabi, yaitu wahdat al-wujud. Pandangan mengenai wahdat al-wujud tidak dimaknai secara leterlek/tekstual bersatunya dua dzat yang berbeda ke dalam satu wujud, melainkan suatu makna di mana seorang sufi yang sudah mencapai ketinggian derajat insan kamil akan merasakan esensi dari realitas absolut, wujud hakiki itu hanya dimiliki Tuhan. Selain Tuhan, maka disebut realitas fana. Sampai pada akhirnya seorang sufi benar-benar merasakan bahwa yang ada hanya Tuhan, yang lain tidak ada, termasuk dirinya. Seorang sufi mengalami fana' dalam asma', sifat, dan dzat Tuhan.

Kedua, dalam mendeskripsikan kedekatan dan rasa cinta yang begitu besar seorang sufi kepada Tuhannya, maka bahasa yang digunakan turut memberikan ekspresi, apa yang tengah dirasakan dan dialami seorang sufi ketika merasakan nuansa kebatinan yang sedemikian dalam kepada Tuhannya. Bahkan jika boleh dikatakan, hampir tidak ada katakata yang mampu merepresentasikan perasaan dan melukiskannya. Oleh sebab itu pilihan kalimat yang digunakan Ibn 'Arabi untuk hal-hal semacam ini senantiasa mengandung makna metafora. Sedangkan al-Jili, dalam pembahasan terkait hal ini selalu memberikan "warning" dengan menambahkan keterangan dan memberikan tekanan kalimat secara eksplisit, bahwa sungguhpun manusia mampu berhias dengan nama dan sifat-sifat Tuhan, ia tetap tidak bisa menyamai nama dan sifat-sifat-Nya. Manusia adalah manusia, dan Tuhan adalah Tuhan.

Ketiga, menurut al-Jili, Tuhan adalah hakekat wujud yang sesungguhnya, yang disebut dzat Mutlak atau realitas murni. Tuhan ada dengan sendirinya (wujud), terdahulu (qidam), serta kekal (baqa'). Selain Tuhan, disebut realitas fana. Alam menurut al-Jili adalah wujud yang diadakan (atas kehendak Tuhan) dari sebelumnya tidak ada ('adam).

Sementara Ibn 'Arabi mempunyai pandangan berbeda, ia mengatakan bahwa alam ini bukan diciptakan dari sesuatu yang tidak ada, melainkan dari sesuatu yang telah ada, yakni yang terdapat dalam ilmu Tuhan. Wujud yang ada dalam ilmu Tuhan itulah yang kemudian muncul sebagai alam nyata. Demikian halnya pandangan mengenai Nur Muhammad, bagi al-Jili, Nur Muhammad adalah huduus (baru) bukan qadim, karena yang qadim hanyalah Tuhan. Sedangkan Ibn 'Arabi menyatakan bahwa Nur Muhammad adalah qadim (dahulu) dalam ilmu Tuhan dan menjadi baru (huduus) saat menyatakan diri pada makhluk. 
Keempat, insan kamil merupakan produk akhir dari proses tajalli Tuhan pada alam semesta, yang mencerminkan citra Tuhan secara utuh. Hal ini dapat tercapai setelah manusia dapat mengembangkan dirinya dengan menyerap asma' dan sifat-sifat Tuhan sebanyak-banyaknya (al-Takhalluq bi akhlaq Allah). Dengan menyerap asma' dan sifatsifat Tuhan sebanyak-banyaknya, mengakibatkan terjadinya transformasi spiritual yang mengubah kepribadian seorang sufi dari tingkat yang rendah ke tingkat yang lebih tinggi, hingga pada akhirnya sampai pada tingkat tertinggi, yakni insan kamil.

Kelima, konsep insan kamil al-Jili, berfokus pada perbaikan kualitas diri di hadapan Tuhan melalui tahapan-tahapan riyadhoh. Bagaimana menumbuhkan kepekaan jiwa, sehingga dapat merealisasikan citra Tuhan dalam kehidupan. Al-Jili membagi insan kamil dalam tiga tingkatan:

1) al-Bidayah atau tingkat permulaan; Mulai dengan merealisasikan asma dan sifatsifat Tuhan pada dirinya.

2) at-Tawassuth atau tingkat menengah; munculnya kehalusan sifat kemanusiaan yang terkait dengan realitas kasih Tuhan.

3) al-Khitam atau tingkat terakhir; merealisasikan citra Tuhan secara utuh, selanjutnya dapat mengetahui rahasia takdir.

Keenam, manusia seutuhnya dalam perspektif Abdul Karim al-Jili adalah manusia yang dapat mengembangkan dirinya dengan menyerap asma' dan sifat-sifat Tuhan sebanyak-banyaknya sehingga mencerminkan citra Tuhan secara utuh. Dalam kaitan ini, Al-Jili dalam konsep insan kamilnya menekankan peningkatan dan pengembangan personality, bagaimana menjadi hamba yang baik di mata Tuhan-Nya (abdullah) sekaligus dapat merefleksikan nilai-nilai abdullah dalam kehidupan sosialnya (khalifatullah). Hal ini tentunya telah tergambar pada diri Nabi Muhammad SAW yang merupakan representasi insan kamil yang sesungguhnya.

\section{KeSIMPULAN}

Insan kamil merupakan ajaran tasawuf al-Jili yang merupakan pengembangan dari konsep tasawuf Ibn 'Arabi yaitu wahdat al-wujud. Pandangan mengenai wahdat al-wujud tidak dimaknai secara leterlek/tekstual bersatunya dua dzat yang berbeda ke dalam satu wujud, melainkan suatu makna di mana seorang sufi dapat menyerap asma' dan sifatsifat Tuhan. Seorang sufi akan merasakan esensi dari realitas absolut, wujud hakiki itu hanya dimiliki Tuhan. Selain Tuhan, maka disebut realitas fana. Sampai pada akhirnya benar-benar merasakan bahwa yang ada hanya Tuhan, yang lain tidak ada, termasuk dirinya. Seorang sufi mengalami fana' dalam asma', sifat, dan dzat Tuhan.

Manusia seutuhnya dalam perspektif Abdul Karim al-Jili dalam Kitab al-Insan alKamil adalah manusia yang terbentuk ketauhidannya berkenaan dengan pengakuan uluhiyah, ahadiyah, wahidiyah, rahmaniyah, dan rububiyah serta dapat merealisasikan nilai-nilai ubudiyah meliputi beberapa maqam seperti Islam, Iman, Saleh, Ihsan, al- 
Syahadah, al-Shiddiqiyah, dan Qurbah melalui proses al-Bidayah, al-Tawassuth, al-Khitam dengan sarananya adalah melalui Tajalli al-Af'al, Tajalli al-Asma', Tajalli al-Shifat, dan Tajalli al-Dzat. Dan sebagai implikasinya adalah terbangunnya hubungan yang baik antara seorang hamba kepada Tuhannya (abdullah) sekaligus dapat merefleksikan nilainilai abdullah dalam kehidupan sosialnya (khalifatullah), hal ini sebagaimana tercermin dalam diri Nabi Muhammad SAW sebagai representasi insan kamil dengan sifat-sifat utama yang dimilikinya, yakni Shiddiq, Tabligh, Amanah, dan Fathonah.

\section{DAFTAR PUSTAKa}

Ahmad, L. O. (2018). Pemikiran Modern Dalam Islam: Konsep, Tokoh, dan Organisasi. Makassar : Alauddin University Press.

Al-Ghazali, I. (2005). Ayyuha al-Walad al-Muhib. Singapura-Jeddah-Indonesia.: AlHaramain.

Ali, Y. (1997). Manusia Citra Ilahi: Pengembangan Konsep Insan Kamil Ibn 'Arabi oleh alJili. Jakarta: Paramadina.

Al-Jili. ( 1975). al-Insan al-Kamil fi Ma'rifat al-Awakhir wa al-Awa'il. Beirut: Dar al-Fikr.

Al-Jili. (tt). al-Kahf wa al-Rahim fi Syarh bi-Ism Allah al-Rahman al-Rahim. Kairo: alMaktab al-Muhammadiyah al-Tijariyah.

Al-Naisaburi, A. a.-Q.-K.-Q. ( 434 H). Al-Risalah al-Qusyairiyyah fi 'Ilm al-Tashawwuf. Beirut: ar al-Khair.

Al-Taftazani, A. W.-G. ( 2008 ). Tasawuf Islam, Telaah Historis dan Perkembangannya . Jakarta : Gaya Media Pratama.

Asy’arie, M. (2002). Filsafat Islam Sunnah Nabi dalam Berpikir. Yogyakarta: LESFI.

Bagus, L. ( 1996). Kamus Filsafat Jakarta. Jakarta: Gramedia: Gramedia.

Hasnawati. (2016). Konsep Insan Kamil Menurut Pemikiran Abdul Karim al-Jili. Jurnal alQalb, Jilid 8 (No. 2), 93.

Jalaluddin. (2003). Teologi Pendidikan. Jakarta: PT Raja Grafindo Persada.

Kesuma, K. M. ( 2018). Insan Kamil Dalam Perspektif Abd al-Karim al-Jili Dan Pemaknaannya Dalam Konteks Kekinian. Jurnal UIN Raden Intan Lampung, 180.

Kholifah, D. U. ( 2018). Tasawuf Akhlaqi Dalam Pemikiran Syaikh Abdul Qadir al-Jailani Dan Relevansinya Dalam Pembentukan Insan Kamil, Tesis. Lampung: Universitas Islam Negeri Raden Intan Lampung.

Martini, H. N. ( 1994). Manusia Berkualitas. Yogyakarta: Gajah Mada University Press.

Muhadjir, N. (1996). Metode Kualitatif. Yogyakarta: Rake Sarasin. 
Muhaimin. (2003). Wacana Pengembangan Pendidikan Islam. Surabaya: PSAPM, kerjasama dengan Pustaka Pelajar Yogyakarta.

Mustofa. (2007). Akhlak Tasawuf. Bandung: CV. Pustaka Setia.

Newman, W. L. (2015). Social Research Methods Qualitative and Quantitative Approache, Boston: Allyn \& Bacon, 1997.- sebagaimana dikutip Muslim dalam Jurnal Wahana, Vol 1, (No. 10), 78. dalam Varian-Varian Paradigma, Pendekatan, Metode, Dan Jenis Penelitian Dalam Ilmu Komunikasi.

Nicholson, R. A. (1981). Studies in Islamic Mysticism. New Delhi: Idarah-i Adabiyat-i Delhi.

Nur, A. F. (2020). Karakteristik Ekspresi Bahasa Metaforis Dalam Tasawufwujudiyah Nusantara. Jurnal Al-Tsiqoh (Dakwah dan ekonomi), Vol. 5 (No. 1), 26.

Rifa'i, A. (1266 H/1851 M). Ri'ayah al-Himmah.

Sudirman, N. e. (1989). Ilmu Pendidikan. Bandung: Remadja Karya.

Sukmadinata, N. S. (2007). Metode Penelitian Pendidikan. Bandung: PT. Remaja Rosdakarya.

Suyuti, A. (1996). Percik-Percik Kesufian. Jakarta: Pustaka Amani.

Toriqqudin., M. ( 2008). Sekularitas Tasawuf, Membumikan Tasawuf dalam Dunia Modern. Malang: UIN Maliki Press.

Ya'qut. (1986). Mu'jam al-Buldan Juz 3. Beirut: Dar al-Shadir.

Yusuf Zaidan, A.-F. a.-S.-K.-J. (1988). Al-Fikr al-Shufi 'inda 'Abd al-Karim al-Jili. Beirut: Dar al-Nahdlah al-'Arabiyah.

Zubair, A. B. (1990). Metodologi Penelitian Filsafat. Yogyakarta: Kanisius. 